\title{
Analysis of Umbrella Shaped Patch Antenna using Different Ground Shapes for UWB Applications
}

\author{
Sabzar Ahmad Bhat \\ Student, Dept. of ECE \\ Lovely Professional University
}

\author{
R. Madhusudhan Goud \\ Astt. Professor Dept. of ECE \\ Lovely Professional University
}

\begin{abstract}
A novel design of the microstrip patch antenna is being proposed in this work. The patch antenna has been designed starting from rectangular patch with rectangular ground and ending with an umbrella semicircular shape for both the patch and a ground plane at an operating frequency of $5 \mathrm{GHz}$ in order to enhance the bandwidth of the antenna using HFSS. On simulation it was observed that the $-10 \mathrm{~dB}$ impedance bandwidth of antenna increased from $15.94 \%$ to $43.07 \%$ showing the improvement of $27.13 \%$ with return loss of $37.77 \mathrm{~dB}$ with good VSWR. The semicircular patch with modified circular ground produced a bandwidth of 2.1537 $\mathrm{GHz}$ which can be used for the ultra-wide band (UWB) applications.
\end{abstract}

\section{Keywords}

Umbrella semicircular shape, HFSS, Bandwidth, Return loss, VSWR, UWB.

\section{INTRODUCTION}

Wireless communication is enduring to witness tremendous growth and broad implementation in a wide variety of applications. There has been an increasing worldwide interest in low profile, low-cost, light weight and wideband system designs. One of the most fundamental components of wireless systems is their antenna. Broad bandwidth antennas are always in demand so that various applications are covered by a single antenna. In order to meet these requirements microstrip antenna is a good choice since they have various applications in satellite communications, wireless systems. This antenna can be used in very high-data rate and short range wireless communication systems to modern radar systems [1], [2], [3].

Microstrip antennas are the low profile, economical low weight antennas conformable to planer and non-planer surfaces. These are the one of the useful antennas at the microwave frequencies but have the narrow bandwidth. The microstrip technique is a planar technique used to produce lines carrying signals and antennas coupling such lines and radiated waves [4]. It uses conductive strips and patches formed on the top surface of a thin dielectric substrate separating them from a conductive layer on the bottom surface of the substrate and constituting a ground for the line or the antenna [5]. A patch is typically wider than a strip and its shape and dimension are important features of the antenna. Microstrip antennas are predominantly appropriate for use as active antennas. Active antenna is the antenna having all of the essential components such as an antenna element, a feeding circuits, active devices, inherently provided on a monolithic substrate, thus producing compact, low cost, multifunction antenna equipment [6]. Microstrip patch antennas are undoubtedly the most widely used type of antennas today due to their advantages such as light weight, low volume, low cost, compatibility with integrated circuits and easy to install on the firm surface.

\section{DESIGN METHODOLOGY}

Recent examples of research on wideband microstrip patch design can be found in [6]. Following is the flow chart that describes the steps involved in designing the patch antenna [5], [8]:

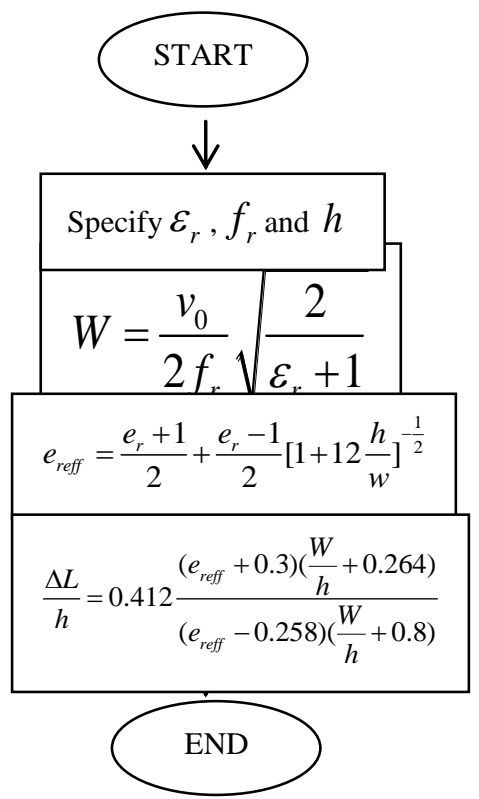

\section{ANTENNA DESIGN AND}

\section{GEOMETRY}

A low profile microstrip monopole patch antenna is proposed as shown in Fig.1. The rectangular and circular geometries were designed and simulated to enhance the performance of an antenna. The two cases of the antenna were designed and simulated starting from the rectangular ground plane and ending up with an umbrella semicircular shape for both the radiating patch and the ground plane.
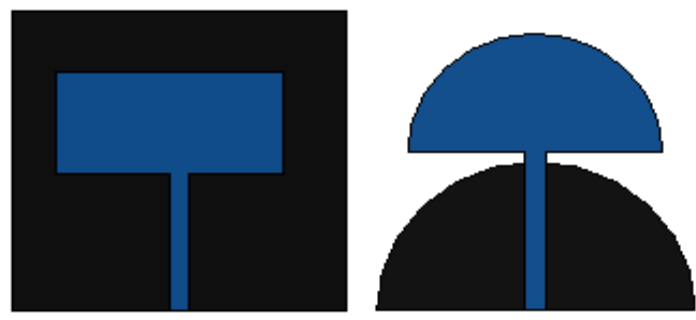

Fig 1: Steps towards the design of final design of proposed patch antenna

For first case, the shape of the rectangular microstrip patch antenna shown in Fig. 2 has a radiator dimensions of $12 \times 24$ $\mathrm{mm}^{2}$ and rectangular ground plane with dimensions of $35 \times 35$ $\mathrm{mm}^{2}$. The resonance frequency of antenna was set at $5 \mathrm{GHz}$. 


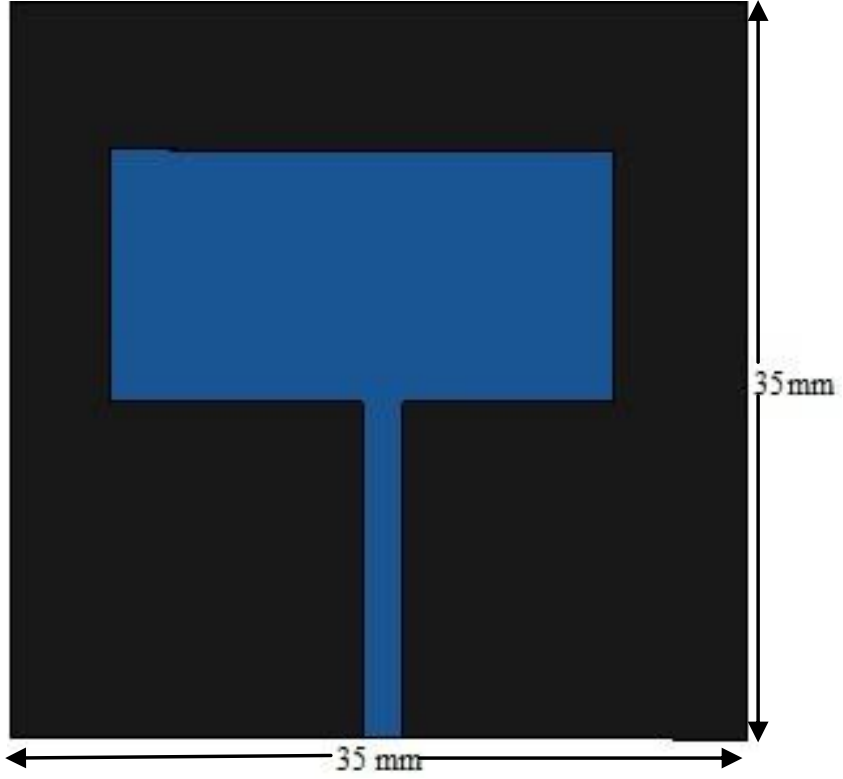

Fig 2: Rectangular microstrip patch antenna with rectangular ground

In second case the umbrella semicircular shapes of both the radiating patch and ground pane was designed with radius $\mathrm{R}$ $\# 1=15 \mathrm{~mm}$ and $\mathrm{R} \# 2=12 \mathrm{~mm}$ as shown in Fig. 3. The length of the microstrip feed line that is used is $\mathrm{F} \# \mathrm{~L}=16 \mathrm{~mm}$ with the width of $\mathrm{F} \# \mathrm{~W}=1.9 \mathrm{~mm}$ which is shown in Fig. 4. The antenna was designed on the FR4 substrate with thickness of $4.0 \mathrm{~mm}$ with $\varepsilon_{r}=4.7$.

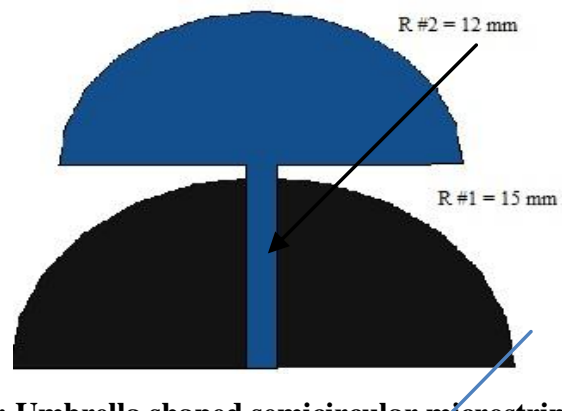

Fig 3: Umbrella shaped semicircular microstrip patch antenna with semicircular/ground

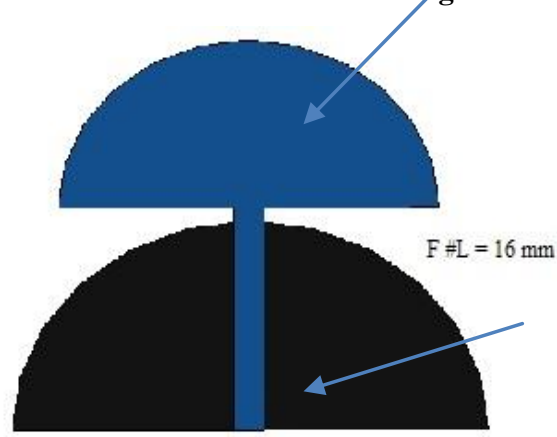

$$
\mathrm{F} \# \mathrm{~W}=1.9 \mathrm{~mm}
$$

Fig 4:

Umbrella shaped semicircular microstrip patch antenna with semicircular ground

\section{SIMULATION AND RESULTS}

The simulation was completed through HFSS v.12 tool from where the reflection coefficient and VSWR was studied to investigate the bandwidth of the antenna on changing the shape of ground and radiating patch. Since the VSWR defines how well matched the antenna is to the transmission line or receiver [7]. It is related to the reflection coefficient by equation 1:

$$
V S W R=\frac{1+|\Gamma|}{1-|\Gamma|}
$$

Where $\Gamma=$ Reflection Coefficient

The bandwidth is calculated as the $-10 \mathrm{~dB}$ impedance bandwidth which is given by equation 2 :

$$
B W=f_{h}-f_{l}
$$

In terms of percentage the bandwidth is given by equation 3 :

$$
B W=\frac{f_{h}-f_{l}}{f_{c}} \times 100
$$

Where $f_{h}=$ highest frequency.

$$
\begin{aligned}
& f_{l}=\text { lowest frequency. } \\
& f_{c}=\text { centre frequency. }
\end{aligned}
$$

The antenna was matched with the $50 \Omega$ with the transmission line.

Starting with the first case, the rectangular shape for both radiating patch and ground, the dimensions of patch are $12 \times$ $24 \mathrm{~mm}^{2}$ and for ground plane the dimensions are $35 \times 35$ $\mathrm{mm}^{2}$. The simulation results are shown in the Fig. 5 and Fig. 6.

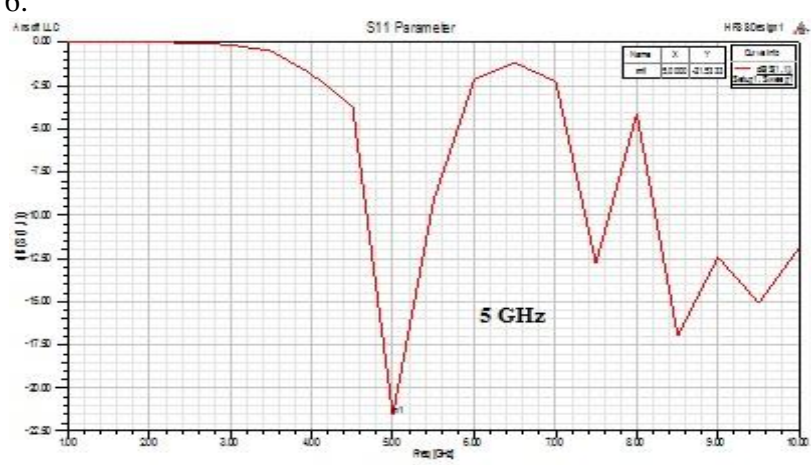

Fig 5: S11 parameter of Rectangular patch antenna with

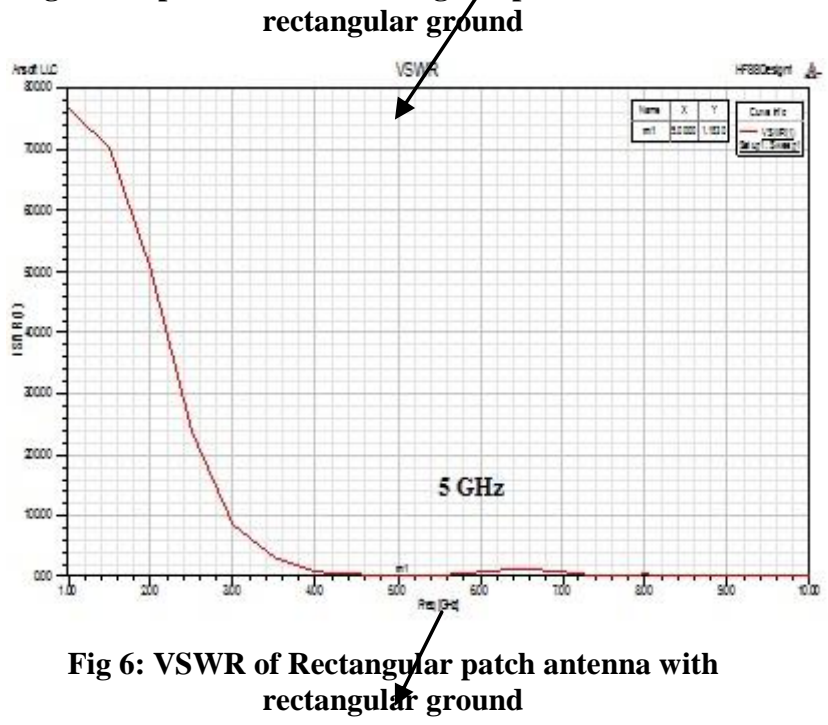


In the final case, the shape of both radiating patch and ground plane were converted to half circular shapes with radius of 12 $\mathrm{mm}$ and $15 \mathrm{~mm}$ respectively and simulation results are shown in the Fig 7 and Fig 8.

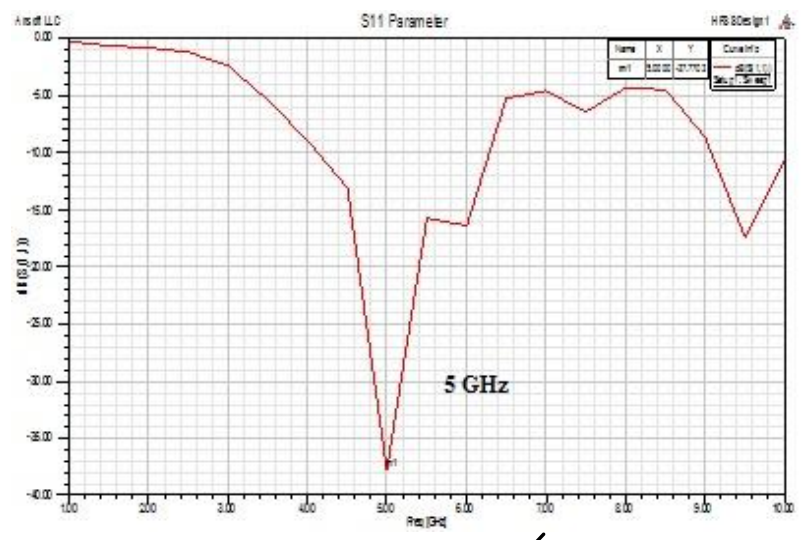

Fig 7: S11 parameter of umbrella shaped semicircular microstrip patch antenna withremicircular ground

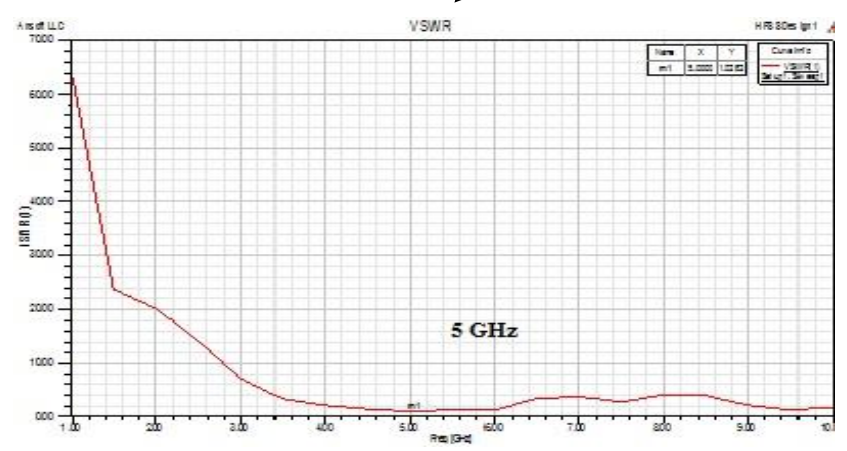

Fig 8: S11 parameter of umbrella shaped semicircular microstrip patch antenna with semicircular ground

\subsection{Comparison between T/wo Antennas}

The comparison between the result of the two cases of the antenna studied on varying the shape of radiating patch and ground plane is shown in Table 1.

Table 1. Comparison between two antennas

\begin{tabular}{|l|c|c|c|c|}
\hline \multicolumn{1}{|c|}{$\begin{array}{c}\text { Antenna } \\
\text { Shape }\end{array}$} & S11 & VSWR & $\begin{array}{c}\text { Band- } \\
\text { width }\end{array}$ & $\begin{array}{c}\text { Percentag } \\
\text { e } \\
\text { Bandwidt } \\
\text { h }\end{array}$ \\
\hline $\begin{array}{l}\text { Rectangular } \\
\text { patch and } \\
\text { ground plane }\end{array}$ & $\begin{array}{c}20.4469 \\
\mathrm{~dB}\end{array}$ & 1.21 & $\begin{array}{c}0.7973 \\
\mathrm{GHz}\end{array}$ & $15.94 \%$. \\
\hline $\begin{array}{l}\text { Semi-circular } \\
\text { patch and } \\
\text { ground plane }\end{array}$ & $\begin{array}{c}-37.770 \\
\mathrm{~dB}\end{array}$ & 1.02 & $\begin{array}{c}2.1537 \\
\mathrm{GHz}\end{array}$ & $43.07 \%$ \\
\hline
\end{tabular}

It is clear from the table that in first case the antenna suffers from the narrow bandwidth and then varying the shape of ground plane and radiating patch the bandwidth of the antennas tends to increase and finally when semi circular shape is attained by both radiating patch and ground antenna bandwidth increases from $15.94 \%$ to $43.07 \%$ with s11 parameter of $-37.770 \mathrm{~dB}$, thus it attains the bandwidth which is required for the ultra-wide-band (UWB) operation.

\section{CONCLUSION}

In this proposed work two cases of the microstrip antenna has been studied starting with the rectangular patch with rectangular ground and ending with umbrella semicircular shape for both patch and ground plane. In 1st case the bandwidth of antenna came out to be $0.7973 \mathrm{GHz}(15.94 \%)$ with good return loss of $-20.4469 \mathrm{~dB}$ but when the shape of both the ground and radiator was changed the bandwidth of the antenna increased up to $2.1537 \mathrm{GHz}(43.07 \%)$ with return loss of $-37.770 \mathrm{~dB}$ with good VSWR. Thus the performance of antenna in terms of bandwidth increases by $27.13 \%$.

\section{REFERENCES}

[1] Z. N. Chen, "UWB antennas: design and application", The $6^{\text {th }}$ International Conference on Information Communications \& Signal Processing, Singapore, ICICS, 2007, pp. 1-5.

[2] Vikas, Er.Baljinder Kaur, Krishan Sherdia,"Microstrip Patch Antenna for UWB Applications", International Journal of Advanced Research in Computer and Communication Engineering Vol. 3, Issue 6, June 2014.

[3] Ang, B.K.and B.K.Chung, "A wideband microstrip patch antenna for 5-6GHZ wireless communication," Progress In Electromagnetics Research, PIER 75, 397-407, 2007.

[4] Osman, H.A., E.A. Aballah, and A. A. Abdel Rhim, "A novel broadband compact circular disk microstrip antenna for wireless applications," PIERS Online, Vol. 4, No. 7, 761-766, 2008.

[5] Constantine A. Balanis,"Antenna Theory Analysis and Design", 3rd edition A John Wiley \& Sons, INC., Publication 2005

[6] F. Yang, X. -X. Zhang, X. Ye, and Y. Rahmat-Samii, “ Wide-Band E Shaped Patch Antennas for Wireless Communications," IEEE Trans.Antennas Propagation., vol. 49, no. 7, pp. 1094-1100, July. 2001.

[7] M. Ali, R. Dougal, G. Yang and H.S. Hwang, Shackelford, A.K., Lee, K.F., and Luk, K.M.: 'Design of small-size wide bandwidth microstrip-patch antennas', IEEE Antennas Propag. Mag., 2003, AP-45, (1), pp. 7583.

[8] Girish Kumar, K.P.Ray,"Broadband Microstrip Antennas ",2003 Artech House, INC.685 Canton Street Norwood, MA 02062.

[9] Ryan Clarke, Roshini Karunarate, Chand Schrader, "Ultra Wideband Antenna", FALL 2004. 